\title{
Research on Influential Mechanism of Emotional Intelligence and Career Success \\ Shuhong Wang ${ }^{*}$, Pei Zheng, Xin Cai \\ Zhongnan University of Economics and Law, Wuhan, China \\ *Corresponding author: Shuhong Wang, Doctor, wwindy2000@126.com
}

\begin{abstract}
The research of emotional intelligence on career success has always been a hot topic. Using survey sample data of 298 employees, this study examined the relationship of emotional intelligence and career success . The results show that: Emotional intelligence has a significant positive effect on career success; Social network benefits plays the mediating role between emotional intelligence and career success; Emotional labor moderates the relationship between emotional intelligence and career success. Key words: emotional intelligence; career success; career competence; career satisfaction; social network benifit; emotional labor
\end{abstract}

\section{Introduction}

Career success is the goal that individual pursue in the whole process of career. In recent years, traditional employment pattern has been broken and the social criteria for measuring the occupational success has begun to change from objective career success (promotion, salary, et al.) to the combination of subjective career success (job satisfaction) and objective career success (professional competitiveness) ${ }^{1}$.

Goleman states that "a person's achievement, 20\% depends on his intelligence, 80\% depends on his emotional intelligence." Emotional intelligence (EI) is "the ability to manage emotions and feelings of their own and others, distinguish the differences between them, and use this information to guide their thinking and action." ${ }^{2}$. People with high emotional intelligence can manage mood swings better and promote positive emotional experience and emotional reactions ${ }^{3}$.

How does the emotional intelligence influence the career success? What is the mechanism? Is the strength of the relationship between the two variables affected by other factors or not? Based on the above background and questions, this study tries to understand the relationship between emotional intelligence and career success and the mechanism between them.

\section{The model and the hypotheses}

\subsection{Emotional intelligence and social network benefits}

EI is an individual's capacity to perceive emotions, regulate and manage those emotions, and utilize those emotions in more constructive cognitive thought ${ }^{4}$.Social network benefits (SNB), it's about the personal interests, may be able to get from social networks including resources and career support ${ }^{5}$.The individual with high emotional intelligence can get more social network benefits by expanding the social network, working effectively and making interpersonal relationship management in daily life. First of all, the staffs with high emotional intelligence have a strong understanding and management capabilities to themselves and others, which enables them are keenly aware of emotional information and clues from others words and deeds, enhance social alertness, get more information and resources. Secondly, the 
high emotional intelligence staffs can clearly distinguish relationship conflict and emotional conflict from the task conflict; on the other hand, they can take the right way to communicate and solve, and those allow them to get support from others. Therefore, we propose:

Hypothesis 1: EI would be positively related to SNB.

\subsection{Social network benefits and career success}

Career success (CS) can be divided into two aspects of internal and external success is an overall of internal feelings and external achievement, including two dimensions of career competence and career satisfaction.

In the actual work process, the more information resources the individual obtained, the more career support he would get, and the more work-related achievements he would make. This can not only strengthen individual career competence, but also meet individual psychological sense of achievement at the same time, and thus enhance individual career satisfaction.

Career support refers to that when the individual meet difficulties in the work process, other people will provide timely help and suppor. It divided into inner organizational support and outer organizational support. When individuals feel the support from the organization, they will increase job satisfaction and reduce turnover intention ${ }^{7}$. What's more, individuals can get a strong psychological capital to help them ensure the work-life balance from outer organizational support, and it has a direct impact on the individual's career and life satisfaction. Therefore, we proposed:

Hypothesis 2: SNB would be positively related to CS.

\subsection{The mediation effect of social network benefits}

According to social exchange theory and social capital theory, people's career success is inseparable from the necessary information and the support or help of others, but these resources and support exist objectively in the social networks, the individuals need to acquire by means of a purpose, then promote career competence and enhance their career satisfaction. In the interpersonal communication process, Individuals with higher emotional intelligence use their own ability advantages to strengthen their continue contact with the outside world to obtain external recognition and support. Therefore, individuals with high emotional intelligence can not only expand their social network size to develop a high-quality social networks relationship, but also get useful information, resources and support from the social networks of objective existence, thus contributing to the successful realization of the individual's own career success. Therefore, we proposed:

Hypothesis 3: SNB partially mediates the relationship between EI and CS.

\subsection{The moderation effect of emotional labor}

EL is the degree of employees demonstrated consistent with the work essential emotion for better work performance. It is a process that the individuals show some emotion purposefully to influence others' emotion to achieve work related goals. In our actual work, organizations always require employees to have a certain emotional labor at work. Employees must control their own emotion. Studies show that employees at least provide three different forms of labor (mental, physical and emotional labor) in order to obtain the corresponding return in the organization. Different jobs have different proportions of the three forms of labor. At higher 
emotional labor work, individuals need to have a higher emotional control and a higher ability to meet the work requirements, that is, individuals need higher emotional intelligence, so if the employees want to achieve career success, the more emotional labor required the job, the greater depend on the individuals' emotional intelligence. Therefore, we proposed:

Hypothesis 4: EL moderates the relationship between EI and CS.

\section{Measurement and tools}

Emotional Intelligence was measured using the Wong \& Law Emotional Intelligence Scale (WLEIS) which consists of four dimensions and comprised 16 items $^{8}$. Each item of the WLEIS was answered on 7-point Likert-type scale.

Career Success Scale Career success consists of two dimensions of career satisfaction and career competence, measured by the scale developed by Greenhaus and Eby ${ }^{9}$, there are tollay 11 items, using 5-point Likert-type scale.

Social Network Benefits was measured using the scale developed by Ning Liu ${ }^{10}$, including two dimensions of career support and resources. There are tollay 18 items, using a 5-point Likert-type scale.

Emotional Labor Scale developed by Adelmann was used ${ }^{11}$. Emotional Labor comprised of 5 items in this scale, using a 7-point Likert-type scale.

\section{Results}

\subsection{Descriptive statistics}

Table 1 reports the means, standard deviations, and correlations among the study's variables.

Table 1 - Descriptive statistics

\begin{tabular}{|l|c|c|c|c|c|c|}
\hline Variables & Mean & SD & 1 & 2 & 3 & 4 \\
\hline 1. Emotional Intelligence & 5.01 & .94 & $(.93)$ & & & \\
\hline 2. Social Network Benefits & 3.15 & .69 & $.52^{* *}$ & $(.95)$ & & \\
\hline 3. Career Success & 3.48 & .70 & $.45^{* *}$ & $.55^{* *}$ & $(.92)$ & \\
\hline 4. Emotional Labor & 4.97 & 1.04 & $.40^{* *}$ & $.39^{*}$ & $.39^{*}$ & $(.92)$ \\
\hline
\end{tabular}

Note: $\mathrm{N}=289 .{ }^{*} \mathrm{p}<.05 ;{ }^{* *} \mathrm{p}<.01$; Diagonal represents internal consistency for each measure.

We can find from Table2 model1, the results indicate that the positive relationship exists between EI and SNB(r=0.35, $\mathrm{p}<0.001)$, SNB and CS( $\mathrm{r}=0.51, \mathrm{p}<0.001)$. Hypothesis1 and 2 are verified.

From Table2 model2, we can find that there is a positive relationship between EI and CS $(\mathrm{r}=0.46, \mathrm{p}<0.001)$, when we add SNB to the model2, the positive relationship still exist, but it become weakened, that means SNB partially mediated the relationship between EI and CS. Hypothesis3 is verified

We can see from Table2 model3, the regression coefficient of interaction term of EI and EL is 0.24 ( $<<0.001$ ), the results support Hypothesis 4. Figure 1 shows the strength of the relationship between EI and CS at different levels of EL. As can be seen from the Figure 1, there is a stronger relationship at higher emotional labor level. Hypothesis 4 is verified. 
Table 2 - The relationship between EI SNB and CS

\begin{tabular}{|l|c|c|c|c|c|}
\hline \multirow{2}{*}{ Variables } & \multicolumn{2}{|c|}{ model1 } & \multicolumn{2}{c|}{ Model2 } & Model3 \\
\cline { 2 - 6 } & $\mathrm{SNB}(\beta)$ & $\mathrm{CS}(\beta)$ & $\mathrm{CS}(\beta)$ & $\operatorname{CS}(\beta)$ & $\operatorname{CS}(\beta)$ \\
\hline EI & $.35^{* * * *}$ & & $.46^{* * *}$ & $.22^{* * *}$ & $.32^{* *}$ \\
\hline SNB & -11.09 & $.51^{* *}$ & & $.45^{* * *}$ & \\
\hline EL & & & & & $.41^{* * *}$ \\
\hline EI* EL & & & & & $.24^{* * *}$ \\
\hline $\mathrm{R}^{2}$ & $.31^{* * *}$ & $.37^{* * *}$ & $.20^{* * *}$ & $.35^{* * *}$ & $.46^{* * *}$ \\
\hline
\end{tabular}

Note: $\mathrm{N}=289 .{ }^{*} \mathrm{p}<.05 ;{ }^{* *} \mathrm{p}<.01 ;{ }^{* * *} \mathrm{P}<.001 ; \mathrm{EI}^{*} \mathrm{EL}=$ Emotional Intelligence* Emotional Labor

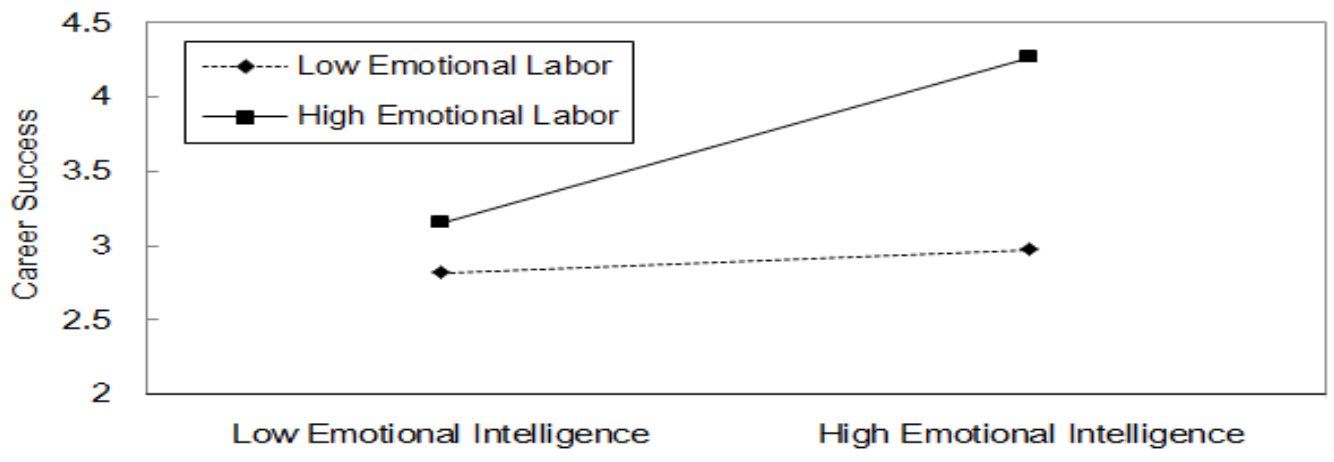

Fig. 1 - Simple slope analysis

\section{Conclusion}

The study examines the relationship between emotional intelligence and career success from the perspective of the social network benefits. The results show that: (1) The individual emotional intelligence positively affect the social network benefits; (2) Social network benefits positively affect career success; (3) Social network benefits plays a mediating role between Emotional Inte-lligence and Career Success; (4) Emotional labor moderates the relationship between emotional inteligence and career success.

\section{Acknowledgements}

This research is supported by the Fundamental Research Funds for the Central Universities (2015S1032) and Hubei provincial high school teching research preject (2014162).

\section{References}

1. L T. Eby, M. Butts, A. Lockwood, Predictors of Success in the Era of Boundaryless Careers. Journal of Organizational Behavior. 24(2003)689-708.

2. J. D.Mayer, P. Salovey, What is emotional intelligence? In P. Salovey, \& D. Sluyter (Eds.). Emotional development and emotional intelligence: Educational implications. New York: Basic Books. 21(1997)3-31.

3. D. H. Kluemper, T. DeGroot, S. Choi, Emotion Management Ability: Predicting Ta-sk Performance, Citizenship, and Deviance. Journal of Management. 39(2013)878-905.

4. J. D. Maye, P. Salovey, D. R. Caruso, Models of emotional intelligence. In R. J.Sternberg (Eds.), Handbook of Intelligence Cambridge, UK, 2000, 396-420.

5. Ning Liu, An Empirical Research on the Relationship between Social Network and Managers’ Career Success. Nankai Business Review. 10(2007)69-77. 
6. C. T. H. Miners, It Is Who You Know and What You Know: An Examination of the Relations among Emotional Intelligence, Social Network Centrality, and Performance. Unpublished Doctoral Dissertation, University of Toronto. 2008.

7. Yi Han, Jingzhe Liu, Person-organization Fit, Perceived Organizational Support and Turnover Intention. Economic Management Journal. 31(2009)84-91.

8. C. S. Wong, K. S. Law, The effects of leader and follower emotional intelligenc on performance and attitude: An exploratory study. The Leadership Quarterly. 13(2002)243-274.

9. L. T. Eby, M. Butts, A. Lockwood, Predictors of Success in the Era of Bound-aryless Careers. Journal of Organizational Behavior. 24(2003)689-708.

10. Ning Liu, An Empirical Research on the Relationship between Social Network and Managers' Career Success. Nankai Business Review. 10(2007)69-77. (In Chinese)

11. P. K. Adelmann, R. B. Zajonc, Facial Efference and the Experience of Emotion. Annual Review of Psychology. 40(1989)249-280. 